\title{
Diverse miRNA spatial expression patterns suggest important roles in homeostasis and regeneration in planarians
}

\author{
CRISTINA GONZÁLEZ-ESTÉVEZ, VARVARA ARSENI, ROSHANA S. THAMBYRAJAH, DANIEL A. FELIX \\ and A. AZIZ ABOOBAKER* \\ Institute of Genetics, Queen's Medical Centre, University of Nottingham, Nottingham, UK
}

\begin{abstract}
RNAs are an important class of non-protein coding small RNAs whose specific functions in animals are rapidly being elucidated. It is clear that miRNAs can play crucial roles in stem cell maintenance, cell fate determination and differentiation. We use planarians, which possess a large population of pluripotent somatic stem cells, as a powerful model system to study many aspects of stem cell biology and regeneration. In particular we wish to investigate the regulatory role miRNAs may have in planarian stem cell self renewal, proliferation and differentiation. Here, we characterized the differential spatial patterns of expression of miRNAs in whole and regenerating planarians by in situ hybridization to nascent miRNA transcripts. These miRNA expression patterns are the first which have been determined for a Lophotrocozoan animal. We have characterized the expression patterns of 42 miRNAs in adult planarians, constituting a complete range of tissue specific expression patterns. We also followed miRNA expression during planarian regeneration. The majority of planarian miRNAs were expressed either in areas where stem cells (neoblasts) are located and/or in the nervous system. Some miRNAs were definitively expressed in stem cells and dividing cells as confirmed by in situ hybridisation after irradiation. We also found miRNAs to be expressed in germ stem cells of the sexual strain. Together, these data suggest an important role for miRNAs in stem cell regulation and in neural cell differentiation in planarians.
\end{abstract}

KEY WORDS: planarian, miRNA, expression, Schmidtea mediterranea, regeneration

\section{Introduction}

The discovery of miRNAs uncovered an underlying method of gene regulation that was almost completely unknown little over a decade ago. miRNAs are an abundant class of non-proteincoding small RNAs (Lee et al., 1993) that may collectively be the largest group of regulatory genes in animal genomes. Since their ubiquity was first demonstrated in 2001 (Lagos-Quintana et al., 2001; Lau et al., 2001; Lee and Ambros, 2001), thousands of miRNAs have been identified in animals, plants and viruses (Griffiths-Jones et al., 2006), with many of them being evolutionarily conserved (Pasquinelli et al., 2003; Prochnik et al., 2007). Recent studies suggest that miRNAs regulate gene expression in more than $30 \%$ of protein coding genes in humans and other animals (Berezikov et al., 2005). miRNAs regulate gene expression by exact complementarity dependent cleavage of the tar- geted mRNA in plants (but rarely in animals), and by inhibiting translation through imperfect complementarity to target sites in animal genes (Lai, 2002; de Moor et al., 2005; Robins and Press, 2005; Stark et al., 2005; Sun et al., 2005). In this way, miRNAs regulate multiple biological processes, including developmental timing (Reinhart et al., 2000), stem cell division (Houbaviy et al., 2003; Hatfield et al., 2005), apoptosis (Cheng et al., 2005; Cimmino et al., 2005) and there inappropriate activity contributes to disease (Álvarez-García and Miska, 2005), including cancer (Meltzer, 2005).

miRNAs have previously been described in planarians (Palakodeti et al., 2005), including both conserved miRNAs present in other phyla as well as some that may be specific to

Abbreviations used in this paper: LNA, locked nucleic acid; miRNA, microRNA.

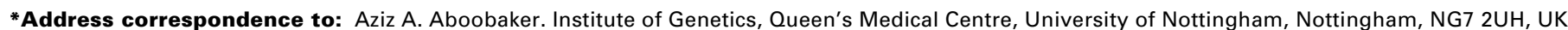
Fax: +44-(0)-115-823-0338. e-mail: aziz.aboobaker@nottingham.ac.uk
}

Supplementary Material for this paper is available at: http://dx.doi.org/10.1387/ijdb.082825cg

Accepted: 19 November 2008. Published online: 5 January 2009. Edited by: Brigitte Galliot. 
planarians. Planarians are bilaterally symmetrical metazoans, members of the phylum platyhelminthes within the major protostome clade, the lophotrocozoa (Carranza et al., 1997; Dunn et al., 2008). Planarians are well known for their incredible regenerative capacity (Morgan, 1900); tiny fragments of their bodies can regenerate into an entire animal perfectly scaled to the new size. Planarian tissues contain several differentiated nonproliferating cell types, with all mitotically active cells currently grouped together as neoblasts. Neoblasts reside in the parenchymal tissue and are believed to be pluripotent somatic stem cells which through proliferation and correct differentiation are responsible for the regenerative capacity of planarians. Together with their immediate progeny, neoblasts account for approximately $20-30 \%$ of all parenchymal cells (Baguñà, 1976). The proliferative capacity and demonstrable multi-potency of the neoblast cell population allow planarians to have extreme tissue plasticity, which is apparent not only in their regenerative capacity but also in their ability to remodel their body pattern indefinitely in response to rounds of starvation and feeding (Saló, 2006).

Palakodeti et al. (2005) reported the cloning of $71 \mathrm{miRNAs}$ from the planarian Schmidtea mediterranea. Given the fact that in other organisms miRNAs have been implicated in the control of stem cell function, cell lineage decisions and cell differentiation, it seems likely that miRNAs play a central role in regulating regeneration and normal homeostatic turnover in planarians.

Although whole-mount in situ hybridization (ISH) is a powerful technique for detecting gene expression in planarians (Umesono et al., 1997; Sánchez Alvarado et al., 2002; González-Estévez et al., 2007), sub-cellular localization of transcripts has not been previously described in these organisms. For instance, in Drosophila, typical mRNAs are predominantly observed in the cytoplasm but primary miRNA transcripts have been detected as nascent transcripts at each chromosomal locus in the nucleus (Kosman et al., 2004; Ronshaugen and Levine, 2004). This approach seems to have broader success than others, in Drosophila at least, and circumvents the high cost of approaches using Locked Nucleic Acids (LNA) (Aboobaker et al., 2005; Wienholds et al., 2005). We have used this approach to examine the expression of Schmidtea mediterranea miRNAs. We clearly show that the sub-cellular localization of planarian mRNAs is predominantly in the cytoplasm, but nascent transcripts can also be faintly detected in the nuclei. Use of long probes against the primary miRNA transcript detects transcripts exclusively in the nucleus while detection with LNA probes shows exclusive localization in the cytoplasm. We see the full spectrum of tissue specific and expression patterns described for other planarian genes. Although we detect miRNAs in all tissues we find that the majority of planarian miRNAs have enriched expression in the central nervous system (CNS) and in the parenchyma. Some conserved miRNAs also have expression patterns that may be conserved with respect to their tissue specific expression in other bilaterians, including some stem cell-related miRNAs. These expression patterns suggest possible conserved functions in both stem cell and germ stem cell regulation for phylogenetically conserved miRNAs for which functions are not yet known in other organisms. Finally, we show that most planarian miRNAs are differentially regulated during regeneration. Overall our data suggest an important role of planarian miRNAs in stem cell regulation, stem cell differentiation during regeneration, neural regeneration and dif- ferentiation and pattern maintenance.

\section{Results}

Design of primary miRNA in situ probes in S. mediterranea

It has previously been shown that short conventional nucleic acid probes corresponding to the pre-miRNA or to the mature miRNA sequences fail to give signals but that longer probes to the primary transcript of the pri-miRNA can detect nascent miRNA transcripts (Aboobaker et al., 2005). We generated long 400700bp digoxigenin-labeled antisense genomic probes to all known Schmidtea mediterranea miRNA loci including the putative planarian specific miRNAs (Palakodeti et al., 2006) (Supplementary Table) and hybridized them as described in Materials and Methods. Where a few miRNAs resided in a small cluster, as is the case for: sme-mir-2a-1/sme-mir-71a-1, sme-mir-2a-2/sme-mir-71a-2, sme-mir-2c/sme-mir-71c, sme-mir-277c/sme-mir-277d, sme-mir750/sme-mir-755, we designed only one probe to span each cluster. When multiple miRNAs resided in a long cluster we designed non-overlapping sub-cluster probes for the following clusters: sme-mir-277a/sme-mir-277b (two probes) and the smemir-2d/sme-mir71b/sme-mir-752 cluster (three probes, one including sme-mir-2d, sme-mir-71b and sme-mir-752, another which included sme-mir-71b and sme-mir-2d and the last including smemir-752). sme-mir-13 had been assigned to this cluster (Palakodeti et al., 2006) but the stem-loop sequence we found in the $S$. mediterranea genome trace archive (http://genome.wustl.edu) had several mismatches compared to the described sequence, so we excluded it from our analyses. This is consistent with the fact that Palakodeti et al. (2006) were not able to clone this miRNA in their extensive screen.

In designing our probes we attempted to minimize the possibility of including host gene exons for those miRNAs that may be intronic (The current $S$. mediterranea genome assembly does not allow for this to be done unambiguously). For corroborating that the probe templates did not include the host gene exons we performed BLAST searches and looked for predicted open reading frames in our probe template sequences and the regions surrounding them. We found no putative open reading frames longer than $100 \mathrm{bp}$ within our probes or for $300 \mathrm{bp}$ either side on the same strand as the miRNAs suggesting that our probes are likely to be all non-coding. More significantly none of our templates had significant BLAST similarity to any known gene (EValue $\geq 0.1$ ) except for the antisense strand to sme-mir-C probe template sequence. This miRNA is embedded in the antisense strand of an S. mediterranea gene with homology to Djcbc-1 (EValue 9e-09), a DEAD box RNA helicase of the RCK/p54/Me31B family in Dugesia japonica. The expression pattern of this DEAD box RNA helicase in $S$. mediterranea (data not shown) was the same pattern as that known for $D$. japonica (Yoshida-Kashikawa et al., 2007) and different to the expression pattern of the strand giving rise to sme-mir- $\mathrm{C}$ (see below).

We also performed a BLAST (blastn, tblastn) against all the planarian ESTs available from NCBI. sme-mir-61 was the only miRNA present in ESTs (E-value 0; NCBI Accession numbers: DN302088, DN308595, DN298481, DN306489), corresponding to a gene of unknown function without a clear open reading frame. Finding pri-miRNA transcripts in smaller EST collections is rare, but nonetheless pri-miRNAs do appear among EST collections. 
TABLE 1

\section{GROUPING OF THE DIFFERENT EXPRESSION PATTERNS OF PLANARIAN mIRNAS}

\begin{tabular}{|c|c|c|c|c|}
\hline Group & miRNA & Adult expression pattern & Sexual strain & Irradiation sentitive \\
\hline \multirow{2}{*}{1} & sme-mir-2b & digestive system (10/15) & & not determined \\
\hline & sme-mir-10 & digestive system (11/15) & & not determined \\
\hline 2 & sme-mir-Ea & digestive system, brain ganglia (14/15) & & not determined \\
\hline 3 & sme-mir-749 & epidermis $(24 / 24)$ & & No \\
\hline \multirow{2}{*}{4} & sme-mir-1a & excretory system, parenchyma (15/19) & & No \\
\hline & sme-mir-C & excretory system, parenchyma (25/25) & & $?$ \\
\hline \multirow{3}{*}{5} & sme-mir-1c & brain ganglia, nerve cords (14/15) & & not determined \\
\hline & sme-mir-31b & brain ganglia, nerve cords enhanced posteriorly $(34 / 34)$ & & No \\
\hline & sme-mir-124c & entire CNS (nerve cords enhanced posteriorly) (11/15) & & not determined \\
\hline 6 & sme-mir-87b & brain ganglia, pharynx (34/34) & & No \\
\hline 7 & sme-mir-7c & brain ganglia, nerve cords, parenchyma including midline $(15 / 15)$ & & $?$ \\
\hline \multirow{5}{*}{8} & sme-bantam-a & medial parenchyma, partial posterior midline $(15 / 15)$ & & not determined \\
\hline & sme-lin-4a & medial parenchyma, partial posterior midline $(18 / 19)$ & & No \\
\hline & sme-lin4c & medial parenchyma, partial posterior midline $(19 / 19)$ & Sexual/germline (4/6) & No \\
\hline & sme-mir-7a & medial parenchyma, partial posterior midline $(15 / 15)$ & & not determined \\
\hline & sme-mir-277c/277d & medial parenchyma, partial posterior midline $(15 / 15)$ & & not determined \\
\hline \multirow{20}{*}{9} & sme-bantam-b & medial parenchyma, brain ganglia $(15 / 15)$ & & not determined \\
\hline & sme-bantam-c & medial parenchyma, brain ganglia $(15 / 15)$ & & not determined \\
\hline & sme-let-7b & medial parenchyma, brain ganglia $(24 / 24)$ & & No \\
\hline & sme-mir-1b & medial parenchyma, brain ganglia $(13 / 15)$ & & not determined \\
\hline & sme-let-7c & medial parenchyma, partial posterior midline, brain ganglia (19/19) & & Yes \\
\hline & sme-mir-2a-1/71a1 & medial parenchyma, partial posterior midline, brain ganglia (19/19) & & No \\
\hline & sme-mir-2a-2/71a2 & medial parenchyma, partial posterior midline, brain ganglia (17/19) & & No \\
\hline & sme-mir-2c/71c & medial parenchyma, partial posterior midline, brain ganglia (19/19) & & Yes \\
\hline & sme-mir-67 & medial parenchyma, partial posterior midline, brain ganglia (18/19) & Sexual/germline (4/6) & Yes \\
\hline & sme-mir-79 & medial parenchyma, partial posterior midline, brain ganglia (15/15) & & not determined \\
\hline & sme-mir-281 & medial parenchyma, partial posterior midline, brain ganglia $(16 / 19)$ & Sexual $(6 / 6)$ & No \\
\hline & sme-mir-745 & medial parenchyma, partial posterior midline, brain ganglia (18/19) & & No \\
\hline & sme-mir-746 & medial parenchyma, partial posterior midline, brain ganglia (14/15) & & not determined \\
\hline & sme-mir-747 & medial parenchyma, partial posterior midline, brain ganglia (17/19) & & $?$ \\
\hline & sme-mir-2d/71b/752 & parenchyma, brain ganglia $(19 / 19)$ & Sexual $^{\star}(6 / 6)$ & Yes \\
\hline & sme-mir-7b & parenchyma, brain ganglia $(19 / 19)$ & & Yes \\
\hline & sme-mir-36 & parenchyma, brain ganglia (17/19) & Sexual/germline (5/6) & Yes \\
\hline & sme-mir-92 & parenchyma, brain ganglia $(16 / 19)$ & & Yes \\
\hline & sme-mir-124a & parenchyma, brain ganglia $(19 / 19)$ & & Yes \\
\hline & sme-mir-124b & parenchyma, brain ganglia $(19 / 19)$ & & Yes \\
\hline 10 & sme-mir-756 & not determined & Sexual/germline (6/6) & not determined \\
\hline
\end{tabular}

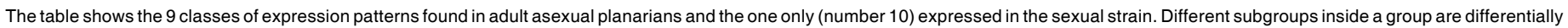

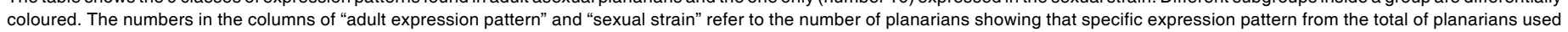

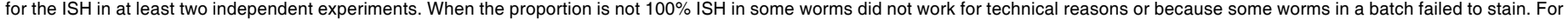

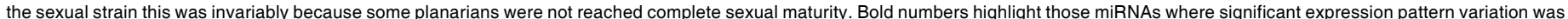

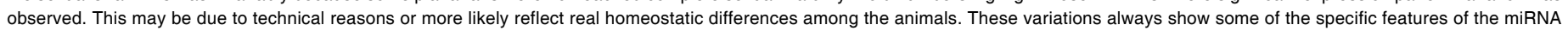

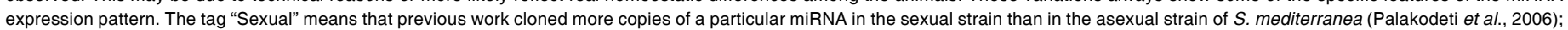

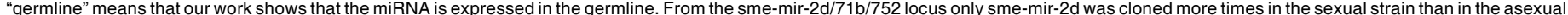

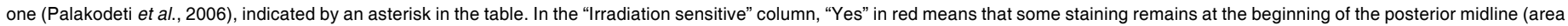
A in Supplementary Fig. 8). A question mark means that it was not possible to unambiguously clarify if all parenchymal staining was lost in irradiated worms.

These analyses suggest our probes will detect bona fide nascent transcripts including the miRNA hairpin sequences of interest, rather than cytoplasmic mRNAs that contained miRNA sequences in their introns.

\section{Spatial expression patterns of miRNAs in adult asexual planarians}

We performed whole-mount in situ hybridization (ISH) for all known planarian miRNAs (see Supplementary Table, Table 1, Fig. 1 and Supplementary Fig. 1). ISH for every miRNA was performed in at least 3 independent experiments and with a total of at least 5 planarians per miRNA per experiment (Table 1). For some miRNAs we noted a consistent variation in ISH patterns. In particular around $1 / 3$ of the animals had alternative expression patterns for sme-mir-31b and sme-mir-C (Supplementary Fig. 2). We believe this may be in part due to technical reasons but may also reflect real homeostatic variation in the expression patterns of these miRNAs.
Identical expression patterns were always generated using different probes to the different miRNAs of a miRNA cluster, consistent with coordinate expression of these clustered miRNAs as single primary transcripts (see example of cluster sme-mir-2d/ sme-mir-71b/sme-mir-752 in Supplementary Fig. 1W, X). From a total of 71 miRNAs reported in planarians (Palakodeti et al., 2006) we obtained 36 patterns in asexual adult planarians, which represents more than half $(41 / 71)$ of the known miRNAs in planarians.

We found clear examples of miRNAs expressed in a selection of tissue specific patterns and tissue specific combinations (Fig. 1 and Supplementary Fig. 1) including: digestive system (2/41); digestive system and nervous system (1/41); epidermis (1/41); excretory system and/or gland cells and parenchyma (2/41); nervous system (3/41); nervous system and pharynx (1/41); strong nervous system and parenchyma (1/41); parenchyma (8/ $41)$; and strong parenchyma expression with weaker nervous system expression (22/41). 

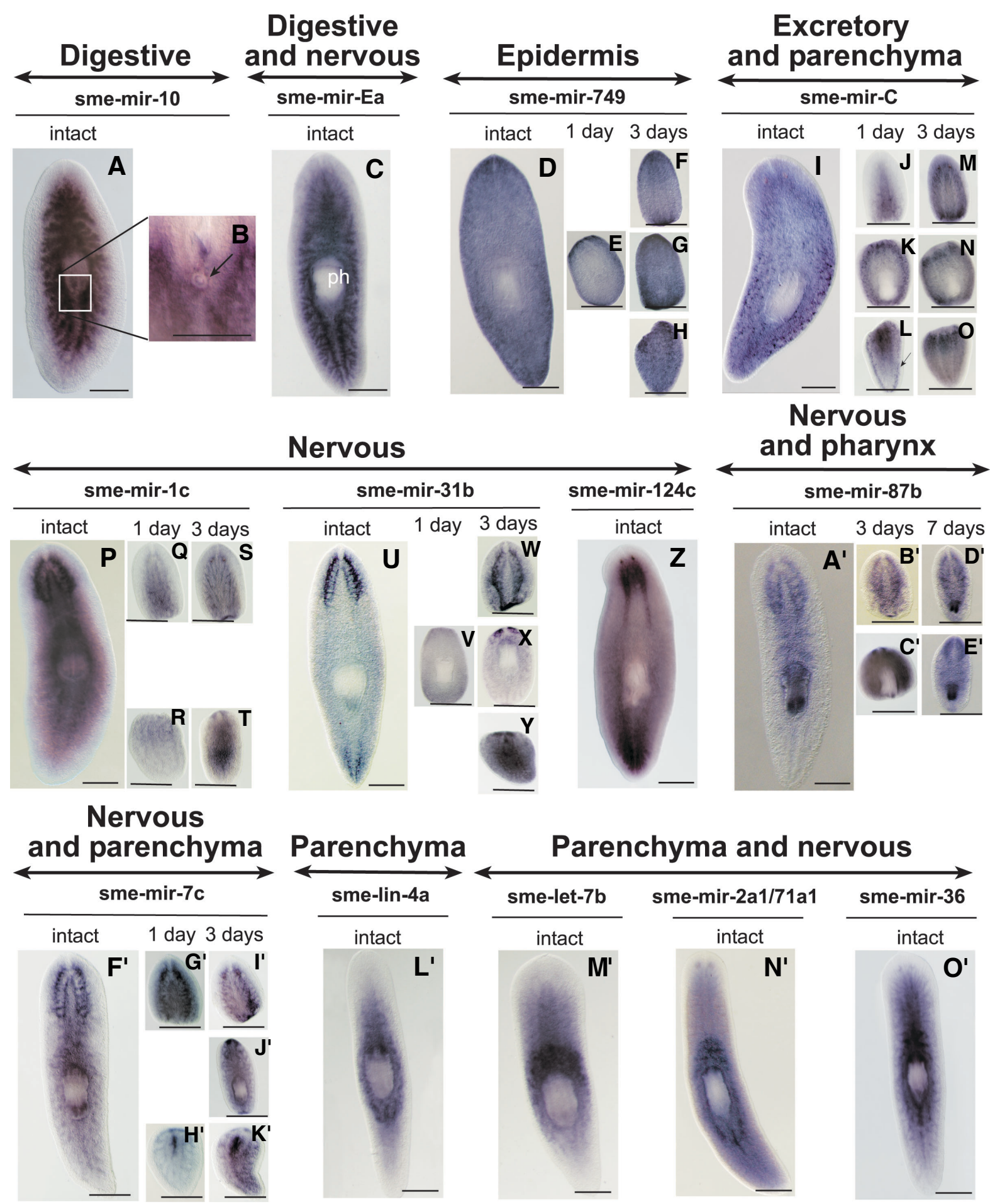

Fig.1. Planarian miRNA expression patterns in asexual intact and regenerating $\boldsymbol{S}$. mediterranea. Whole-mount ISH of the most representative miRNAs in intact and/or regenerating planarians. The different expression patterns can be classified into 9 classes. Representative miRNAs wholemount ISH corresponding to each of the 9 classes are presented (see Table 1). For the regenerating fragments, the levels of amputation are always anterior and posterior to the pharynx (ph). (A,B) sme-mir-10 showing expression in the entire digestive system and in the opening of the pharynx; $B$ shows high magnification of the opening of the pharynx (arrow). (C) sme-mir-Ea showing expression in the posterior branches of the digestive system and in the brain ganglia. (D) sme-mir-749 showing expression in the epidermis. During regeneration its expression is up-regulated in the wound at 1 day of regeneration (E). At 3 days of regeneration expression has increased in the epidermis around the blastema (F-H). (I) sme-mir-C showing expression in the parenchyma, the more posterior part of the excretory system and the subepidermal marginal adhesive gland cells. It is clearly upregulated at $3 d$ of regeneration at the postblastema leve/ (M-O) but not at 1 day of regeneration (J-L) with exception of regenerating tails which present a clear up-regulation in the supepidermal marginal adhesive gland cells (L, see arrow). miRNAs with expression in the CNS are represented by sme- 
Over $70 \%$ (31/41) of the miRNAs have some expression in the nervous system. The planarian CNS consists of two cephalic ganglia situated above two ventral nerve cords (VNCs) that run along all the body of the animal that are connected by transverse commissures (Reuter and Gustafsson, 1995; Cebrià et al., 2002). Most miRNA expression seems to be found surrounding the cephalic ganglia or the cephalic ganglia and the VNCs (Fig. 1). According to previous classification of nervous markers in planarians (Nakazawa et al., 2003), this would correspond to class B genes, which are suggested to be involved in signal transduction to the VNC. An alternate view is that these expression patterns are labelling cells destined or committed to differentiate into cells of the CNS as older neurons die, implicating miRNAs in the process of neural differentiation. One exception to this peri-neural expression is the pattern of sme-mir-124c (Fig.1Z), which, like its homolog in Drosophila, is expressed in the whole CNS (Aboobaker et al., 2005). In contrast expression of mir-124 is limited to the developing brain in vertebrates (Lagos-Quintana et al., 2002). Other conserved nervous-related expression patterns with respect to Drosophila embryogenesis (Aboobaker et al., 2005), can be seen for sme-mir-7c (Fig. 1F') and sme-mir-2c (Supplementary Fig. 1L), sme-mir-7b and sme-mir-92 (Supplementary Fig. 1S, V).

Perhaps most significantly more than $80 \%$ (34/41) of the miRNAs have some parenchymal expression, including the entire or partial midline. The planarian parenchyma is a mesodermal tissue with $20-30 \%$ of the cells in this space being putative neoblasts (Baguñà, 1976). Many of the parenchymal patterns $(15 / 28)$ are specific to the parenchymal region which corresponds to the medial regions of the body surrounding the pharynx and to the more anterior part of the midline posterior to the pharynx (Fig.1L', N' and Supplementary Fig.1C-F, J-R). 7 out of 28 miRNA expression patterns (Fig.1F', O' and Supplementary Fig.1S-X) show the typical expression pattern of proliferating neoblasts in the parenchyma (Salvetti et al., 2000; Orii et al., 2005; Reddien et al., 2005a; Salvetti et al., 2005; Guo et al., 2006; Rossi et al., 2006). A variation on this parenchymal expression pattern is seen for 4 out of 28 parenchymally expressed miRNAs (Fig.1M' and Supplementary Fig.1G-I). These miRNAs sme-let-7b, sme-bantam-b, sme-bantam-c and sme-mir- $1 b$ have expression which is just restricted to the more anterior medial parenchyma and lack expression in the posterior.

Only a few miRNAs are expressed in areas outside of the parenchyma or nervous system. The planarian digestive system is formed by a pharynx and a blind gut with three major branches (two posterior and one anterior) that diverticulate into more lateral

(Legend continued from previous page) tissues and lacks a separate anus (Saló, 2006). 3 miRNAs are expressed in the digestive system, sme-mir-10, sme-mir-Ea and sme-mir-2b. miR-10 expression is detected in the hindgut, posterior primordial midgut and in the anal pad in fully germbandretracted Drosophila embryos (Aboobaker et al., 2005). sme-mir10 (Fig. $1 A, B$ ) is expressed in the entire gut and in the opening of the pharynx, suggesting there may be some conservation of mir10 function in gut tissues across protostome phyla. sme-mir-Ea is only expressed in the posterior part of the digestive system, in addition to the brain ganglia (Fig. 1C). sme-mir-2b (Supplementary Fig. $1 \mathrm{~A}$ ) is expressed in the entire digestive system and in the pharynx. One miRNA, sme-mir-87b, has part of its expression pattern in the pharynx (Fig. 1A') and sme-mir-749 is expressed in cells at or neat the surface of the animal (Fig. 1D and Supplementary Fig. 3), in a similar way to EST clone NCBI: 32899321 (AHNAK-related protein) in Dugesia japonica (Rossi et al., 2007). The excretory system is a dorsal network of canals with specialized flame cells (Saló, 2006). We found that sme-mir-C (Fig. 1I), a specific planarian miRNA and sme-mir-1a (Supplementary Fig. $1 \mathrm{~B})$ are expressed only in the mid-posterior part of the excretory system, in sub-epidermal marginal adhesive gland cells (Sánchez Alvarado et al., 2002) and in the entire parenchyma.

\section{Expression patterns of miRNAs in regenerating planarians}

In order to investigate whether miRNAs play any role during planarian regeneration, we performed whole-mount ISH on regenerating planarians. We used 1 day (a stage when neoblast proliferation is taking place), 3 day (when differentiation is proceeding) and 7 day (when all new structures are essentially in place) regenerating planarian pieces. ISH for every miRNA and regeneration timepoint was performed in at least 2 independent experiments, with a total of at least 3 planarians per miRNA and per regeneration timepoint. Planarians were amputated anterior and posterior to the pharynx and fixed at the appropriate time point.

We observed clearly distinct expression patterns for most of the miRNAs that gave expression in non-regenerating planarians.

sme-mir-749 (Fig. 1D) is expressed at or very close to the epidermis of adult planarians (Supplementary Fig. 3). During regeneration, sme-mir-749 showed expression at or near the epidermis of the anterior and posterior blastemas in 1 day and 3 day regenerating pieces (Fig. 1E-H). sme-mir-C (Fig. 1I) is expressed in the mid-posterior part of the excretory system and subepidermal marginal adhesive gland cells and in the parenchyma. At 3 days of regeneration, sme-mir- $C$ is expressed in the postblastema (Fig. 1J-O). Interestingly, we found that the expression

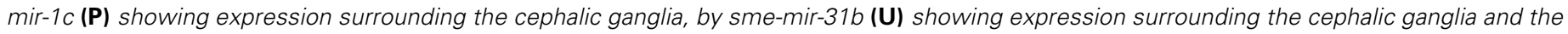

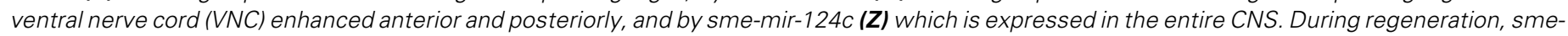

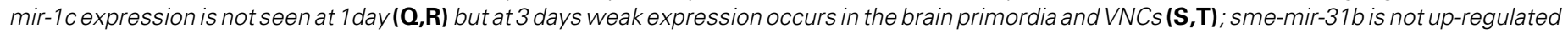

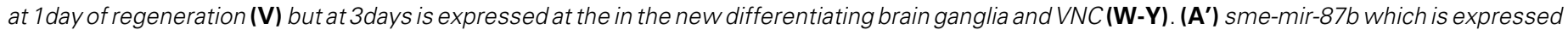

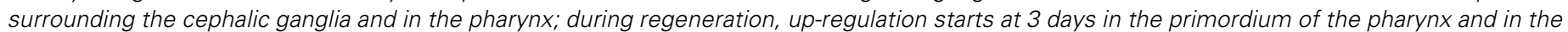

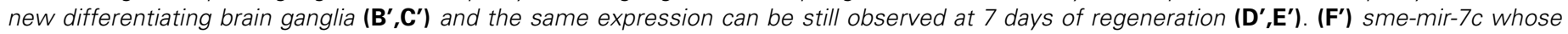

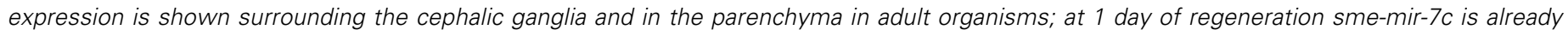

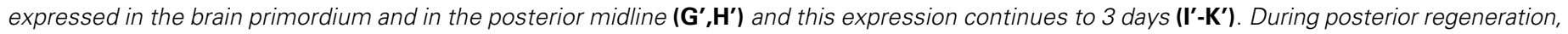

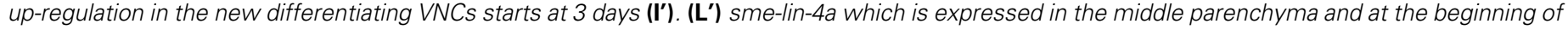

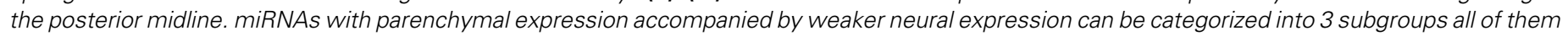

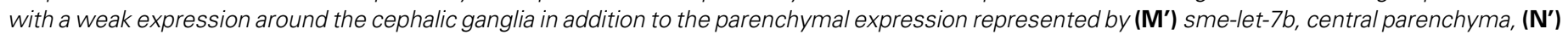

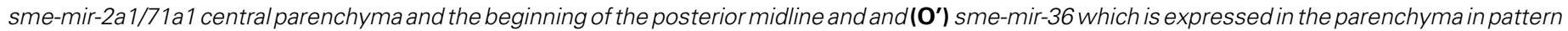
similar to other known neoblast markers. (A-H, $\left.P-G^{\prime}, I^{\prime} L^{\prime}-O^{\prime}\right)$ ventral views; $\left(I-O, H^{\prime}, J^{\prime}-K^{\prime}\right)$ dorsal views. Scale bars indicate 1 mm. 
Fig. 2. Planarian miRNAs expressed in sexually mature planarians. The diagram to the left shows the reproductive system of Schmidtea mediterranea sexual strain. The abbreviations indicate: co, copulatory apparatus; ey, eye; ov, ovary; ovi, oviduct;ph, pharynx; po, genital pore; se, seminal duct; te, testes; yg, yolk gland. sme-lin-4c (A), sme-mir-36 (C), smemir-67(E) and sme-mir-756 (G) wholemount ISH showing expression in the ovaries (black arrow heads), oviduct (black arrows), yolk glands (black asterisk) and in the copulatory apparatus (white arrow). (B,D, F,H) High magnifications from the ovary (black arrow head) region showing part of the oviduct (black arrow). Note that expression of sme-lin-4C (B) has a localised dot at the base of the oviduct while $D$, Fand $\mathrm{H}$ show more dispersed expression profiling the oval shape of the ovary. All images are in ventral position. Scale bars indicate $2 \mathrm{~mm}$.

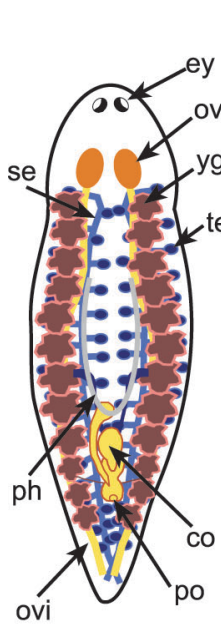

sme-lin-4c
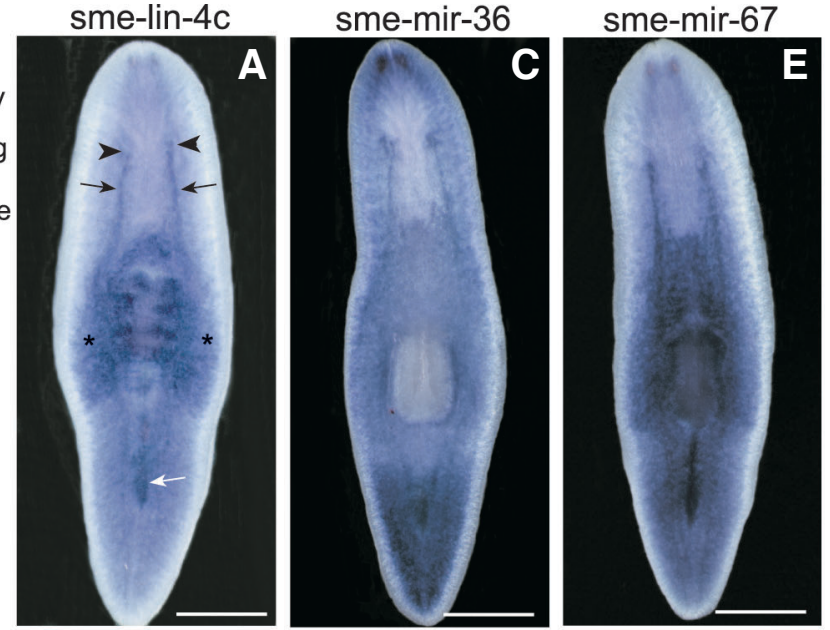

sme-mir-756

B

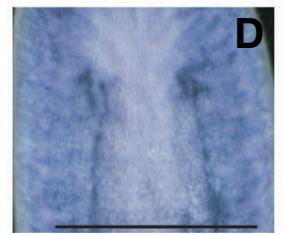

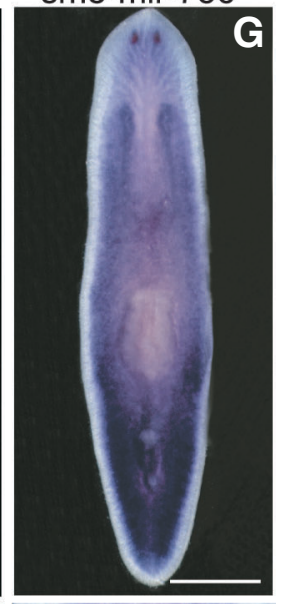

$\mathbf{F}$

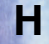

in the sub-epidermal marginal adhesive gland cells was enhanced in 1 day regenerating tails and that this expression disappeared after 3 days (Fig. 1L, O).

For all the miRNAs with predominantly neural expression in whole animals expression was only observed from 3 days of regeneration onwards in the primordial anterior and/or primordial posterior nervous system (for example sme-mir-1c (Fig. 1Q-T), sme-mir-31b (Fig. 1V-Y) and sme-mir-87b (B'-E'). The only exception is sme-mir-7c, where we could detect expression as early as 1 day of regeneration (Fig. $1 \mathrm{H}^{\prime}$ ). sme-mir-7c has strong expression around the brain and less prominent expression in the parenchyma including the midline of intact planarians. During anterior regeneration of tail pieces early neural expression was accompanied by high expression in the posterior midline (Fig. 1H', K'). For sme-mir-87b, where the expression is also in the pharynx of adult animals, as well as the brain, we observed expression of the miRNA in the primordial pharynx later in regeneration (Fig. 1B'-E').

For all the miRNAs with predominantly parenchymal expression patterns we observed more or less expression in the posterior midline in $3 d$ regenerating planarians, similar to the pattern of smemir-7c during regeneration (Supplementary Fig. 4). This pattern is characteristic for neoblast markers (Salvetti et al., 2000; Rossi et al., 2006). In the case of those miRNAs where weak neural expression accompanied parenchymal expression the neural expression did not change during regeneration (Supplementary Fig 4).

\section{Spatial expression patterns of miRNAs in mature sexual planarians}

Palakodeti et al., 2006 observed differences in the number of times miRNAs were cloned from the sexual strain of $S$. mediterrnaea with respect to the asexual strain, suggesting differential miRNA expression between the strains. However, the authors could not observe quantitative differences by Northern blot analyses. In order to elucidate any differential miRNA spatial expression pat- terns in sexual S. mediterranea compared to the asexual strain we performed whole-mount ISH on sexually mature $S$. mediterranea (Table 1). ISH for every miRNA was performed in at least in 2 independent experiments and with at least 3 sexually mature planarians per miRNA (Table 1).

Hermaphrodite $S$. mediterranea have a complex reproductive system formed by ventrally located ovaries posterior to the cephalic ganglia and two dorso-lateral lines of testes and yolk glands (Saló, 2006). Among all the tested miRNAs we could detect expression in the ovaries, oviduct, yolk glands and copulatory apparatus for sme-lin-4c, sme-mir-36, sme-mir-67 and sme-mir756 (Fig. 2), with similar patterns to known markers of the planarian germline (Hase et al., 2003; Zayas et al., 2005; Handberg-Thorsager and Saló, 2007; Wang et al., 2007). Expression in the testes could not be unambiguously detected for any miRNAs, perhaps because this was masked by the higher background we sometimes observe with the nascent transcript ISH protocol we use or because the level of expression is not high enough for clear detection (Zayas et al., 2005). For the other miRNAs the expression in the sexual strain was equivalent to the asexual strain (Supplementary Fig. 5).

Planarian ovaries are round/oval structures organized with the oogonia at the base and periphery and the ova in the lumen of the ovary (Hyman, 1951; Handberg-Thorsager and Saló, 2007). Expression in the ovaries for sme-mir-36, sme-mir-67 and sme-mir756 is slightly different to the expression of sme-lin-4 (Fig 2). The latter seems to be expressed in the lumen of the ovary while the rest are expressed in the periphery where the undifferentiated germ cells or oogonia reside. This suggests that sme-mir-36, sme-mir67 and sme-mir-756 are expressed in germ stem cells in planarians.

\section{Some miRNAs are expressed in planarian stem cells}

Neoblasts are defined as the only proliferating cells in planarians. Cell proliferation in planarians can be abrogated by lethal doses of gamma radiation (Dubois, 1949; Orii et al., 2005; Rossi et 
al., 2007) as it results in the death of all dividing cells. This allows us to compare animals lacking neoblast stem cells with wild type animals. We took advantage of this approach in order to elucidate which miRNAs with parenchymal expression (suggestive of neoblast expression) are actually expressed in cells with proliferative capacity (Table 1).

Asexual planarians were irradiated at lethal doses of gamma radiation and fixed 6 days later when all cells with proliferative capacity have been lost. We were especially interested in the miRNAs which showed a similar pattern to other known neoblast markers (mir-752/2d/ 71b, sme-mir-7b, sme-mir-7c, sme-mir-36, sme-mir-92, sme-mir-124a and sme-mir-124b) and in those that showed expression in germ line associated cells in the sexual strain (smemir-36, sme-mir-67, sme-mir-756 and sme-lin4c).

Of these miRNAs sme-mir-752/2d/71b, sme-

Fig.3. Planarian miRNAs expressed in neoblasts. The figure shows 5 controls versus the 9 miRNAs whose expression, analyzed by whole-mount ISH, is sensitive to high dose gamma radiation. Non-irradiated (A) versus irradiated (B) planarians stained for Smed-GluR which is not affected by irradiation. Nonirradiated (C) versus irradiated (D) planarians stained for cintillo which is not affected by irradiation. Nonirradiated $(\mathbf{E})$ versus irradiated $(\mathbf{F})$ planarians stained for smedwi-2 whose expression is lost after irradiation. Non-irradiated (G) versus irradiated $(\mathbf{H})$ planarians stained for sme-let-7b; the expression of the miRNA is not affected by irradiation. Non-irradiated (I) versus irradiated (J) planarians stained for smemir-31b; the expression of the miRNA is not affected by irradiation. The next miRNAs are all affected by irradiation. Not irradiated (K) versus irradiated (L) planarians stained for sme-mir-71b/2d/752. Non-irradiated (M) versus irradiated (N) planarians stained for sme-mir $7 b$; note that in the irradiated some expression remains in the posterior midline (arrow) as well as around the pharynx. Non-irradiated $\mathbf{( 0 )}$ versus irradiated $\mathbf{( P )}$ planarians stained for sme-mir-36. Non-irradiated ( $\mathbf{Q})$ versus irradiated (R) planarians for sme-mir-92. Non-irradiated (S) versus irradiated (T) planarians for sme-mir124a; note that in the irradiated animals a little of the staining remains in the posterior midline (arrow). Non-irradiated (U) versus irradiated (V) planarians for smemir-124b; note that in the irradiated a little of the staining remains in the posterior midline (arrow). Non-irradiated $(\mathbf{W})$ versus irradiated $(\mathbf{X})$ planarians for sme-let-7c; note that in the irradiated a little of the staining remains around the pharynx (arrow). Non-irradiated $\mathbf{( Y )}$ versus irradiated $(\mathbf{Z})$ planarians for sme-mir-2c/71 C. Non-irradiated ( $\left.\mathbf{A}^{\prime}\right)$ versus irradiated (B') planarians for sme-mir-67; note that in the irradiated a little of the staining remains in the posterior midline (arrow). (A-B, G-J) Ventral views; $\left(C-F, K-B^{\prime}\right)$ dorsal views. Scale bars indicate $1 \mathrm{~mm}$.
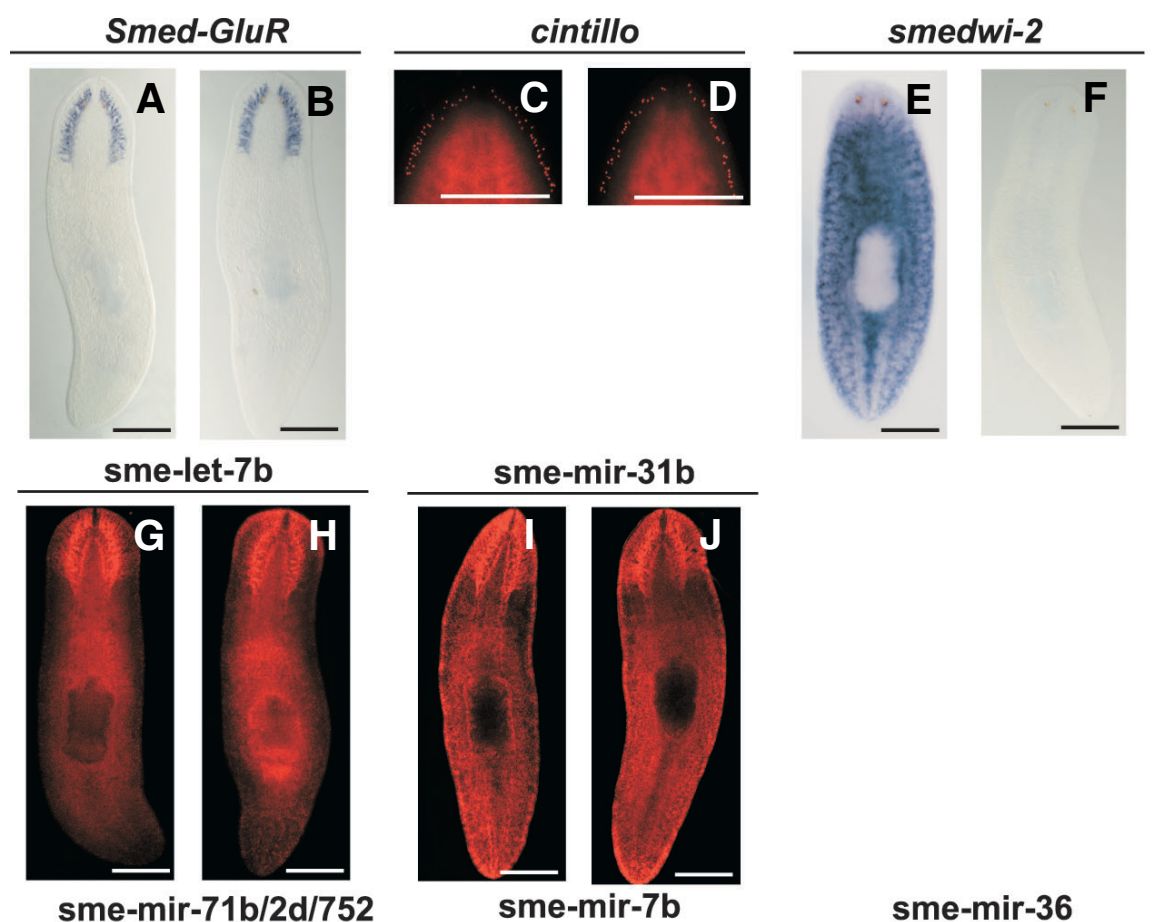

sme-mir-71b/2d/752

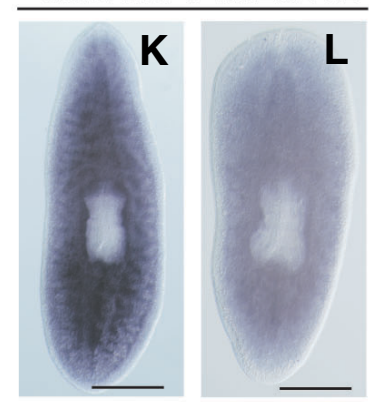

sme-mir-92

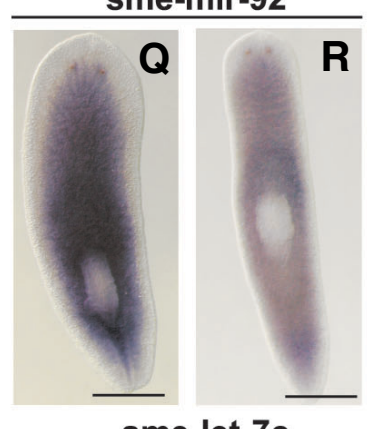

sme-let-7c

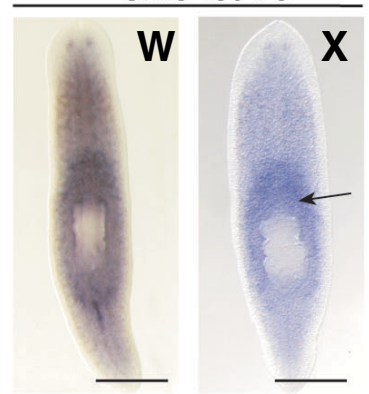

sme-mir-124a
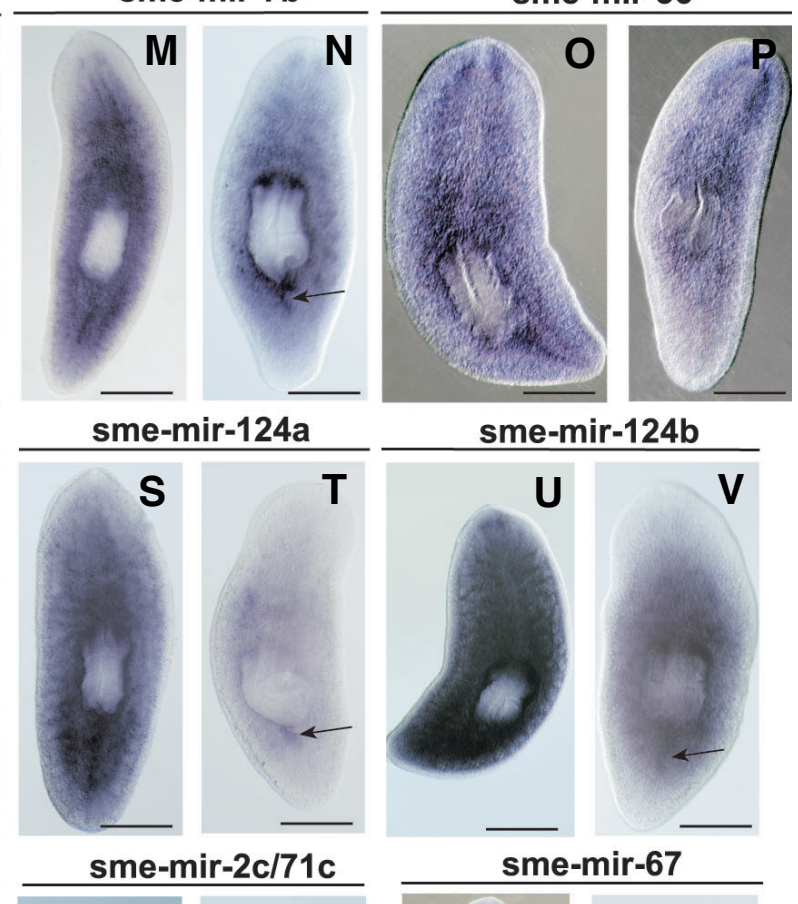

sme-mir-124b
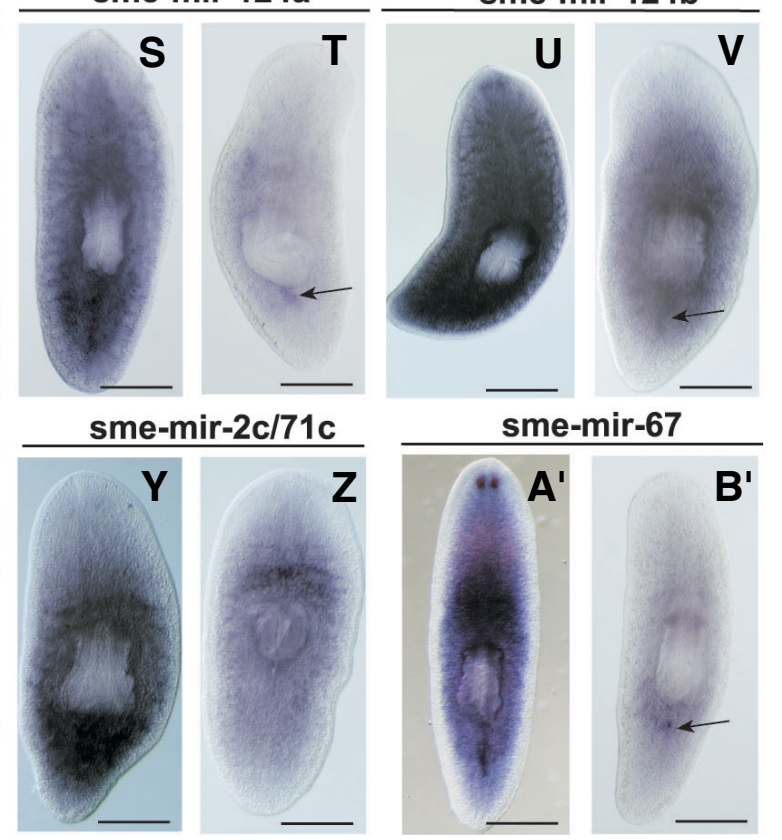

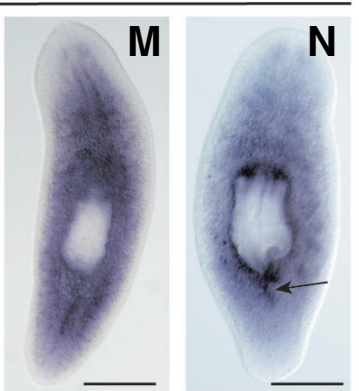


mir-7b, sme-mir-36, sme-mir-92, sme-mir-124a and sme-mir-124b expression are lost or greatly reduced after lethal doses of gamma radiation (Fig. $3 \mathrm{~K}-\mathrm{V}$ ). Tissue specific markers of differentiated cell types like Smed-GluR (F. Cebrià and P. Newmark) or cintillo (Oviedo et al., 2003) were not affected (Fig. 3A-D) whereas expression of smedwi-2 (Reddien et al., 2005a) was completely lost (Fig. 3E, F). For sme-mir-7c loss of parenchymal expression was difficult to interpret as in non-irradiated adults parenchymal expression is faint. The same is true for two other miRNAs, smemir-C and sme-mir-747, where expression in the parenchyma of non-irradiated intact animals is also weak.

We also examined some miRNAs which, although they didn't have the typical expression pattern corresponding to neoblast markers known to date, are expressed in the parenchyma. Most of these, for instance sme-let-7b (Fig. 3G, H), sme-lin-4a, sme-mir1a, sme-mir-2a-1/71a1, sme-mir-2a-2/71a2 and sme-mir-745 (data not shown), were not affected by irradiation. In contrast, sme-let$7 c$ and sme-mir-2c were no longer expressed after irradiation (Fig. 3W-Z).

For the miRNAs with expression in the germline of sexual planarians (see above) we found that sme-mir-36 and sme-mir-67 (Fig. 30-P, A'-B') showed no expression after irradiation in asexual planarians but the expression of sme-lin-4c remained (data not shown). This suggests a correlation between sme-mir-36 and smemir-67 expression in neoblasts and germ cells, which is true of other neoblast/germ line markers (Shibata et al., 1999). In the case of sme-mir-756 we observed no expression in the asexual strain suggesting that it might only be expressed at significant levels in the sexual strain.

As a control, we performed ISH on irradiated animals for some of the miRNAs that clearly seemed to be expressed in differentiated cells, for instance sme-mir-31b (Fig. 3I, J), sme-mir-87b or sme-mir-749 (data not shown) that were not affected by irradiation.

\section{Whole-mount in situ hybridization with LNA probes confirms miRNA expression patterns obtained with nascent transcript probes}

In order to confirm that the miRNA expression patterns we observed using probes to nascent transcripts were indicative of mature miRNA expression we performed whole-mount ISH with LNA probes for two miRNAs, sme-let-7c and sme-mir-67. ISH with LNA probes was successful showing that future work on miRNAs of particular interest can be done with this more costly approach.

We observed the same expression pattern with LNA probes as we observed for our unprocessed transcript probes for sme-let-7c

(Legend continued from opposite page) and sme-mir-67 in asexual organisms (Supplementary Fig. 6). Furthermore, we can say, at least for sme-let-7c and sme-mir-67 that these miRNAs are probably not being post-transcriptionally regulated, at least spatially, in planarians.

\section{Whole-mount fluorescent in situ hybridization with nascent transcript probes show sub-cellular localization to the nucleus}

Sub-cellular localization of typical mRNA transcripts has not been previously described in planarians. In order to confirm that the miRNA expression patterns with nascent probes are detecting primary miRNA transcripts in the nucleus we performed confocal imaging on whole-mount fluorescent ISH for several miRNA nascent probes using one LNA probe and two protein coding genes as controls.

Localization of smedwi-2 (Reddien et al., 2005a) and cintillo (Oviedo et al., 2003) transcripts was, as expected, predominantly in the cytoplasm (Fig. 4A-H). However, increasing the strength of excitation allowed the faint detection of nuclear dots in addition to cytoplasmic expression (Fig. 4B, arrows in the high magnification panel). In addition, localization of smedwi-2 appeared to be perinuclear. In contrast, for all the miRNA nascent probes analysed, sme-mir-749, sme-mir-87b, sme-mir-31b and sme-let-7b the transcript was detected exclusively in the nucleus (Fig. 4I-X). Expression was never observed in the cytoplasm. Cells with a low intensity of fluorescence show 2 dots whereas cells with higher fluorescence stain more broadly in the nucleus (Fig. 4P asterisk). Confocal sections show that sme-let-7c mature transcripts are detected strongly in the dorsal midline and only weakly at the ventral one (Fig. 4Y and Supplementary Fig. 7). We would expect to have a similar dorso-ventral distribution for the other miRNAs with similar midline expression. Finally sme-let-7c LNA probe exclusively detected the mature miRNAs in the cytoplasm (Fig. 4Z-E').

Demonstration of sub-cellular localization confirms the specificity of miRNA nascent probes for the detection of primary miRNAs in the nuclei. It also suggests that further studies of sub-cellular transcript localisation maybe important for identifying those genes expressed in peri-nuclear nuage or chromatoid bodies in planarians.

\section{Discussion}

We have shown that detection of miRNAs in planarians can be achieved by ISH detection using probes to primary miRNA transcripts as previously reported for Drosophila embryos (Aboobaker et al., 2005). We have been able to characterize 41 miRNA expression patterns in the asexual strain and one miRNA expres-

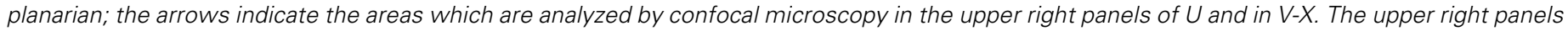

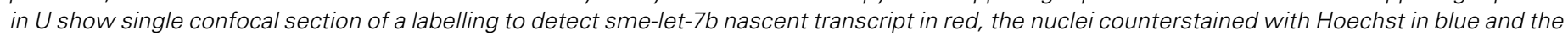

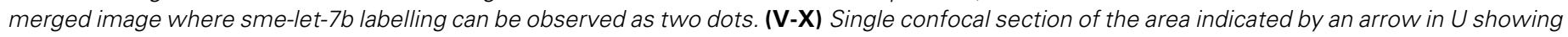

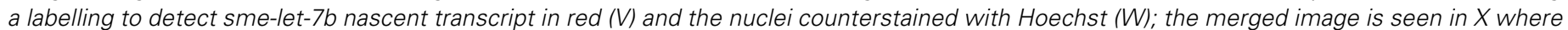

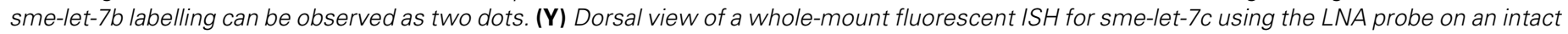

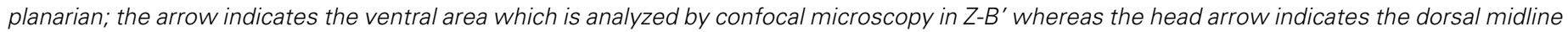

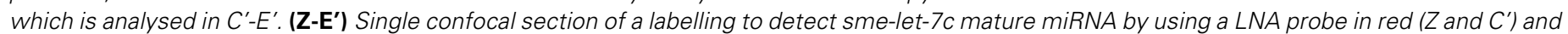

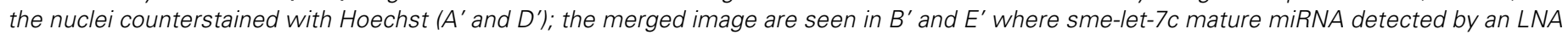

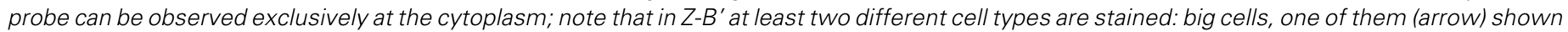

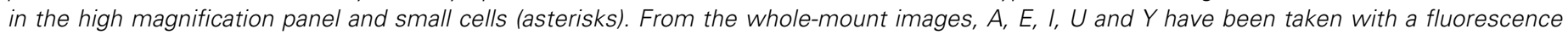

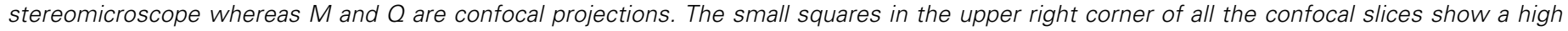

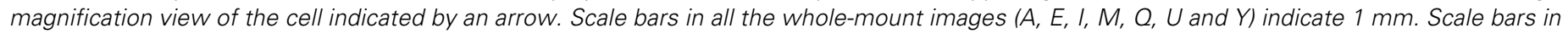
all the confocal sections indicate $20 \mu \mathrm{m}$. 
Fig. 4. Sub-cellular localization of mRNAs, miRNA nascent transcripts and miRNA mature transcripts. This figure illustrates that mRNAs of typical genes predominantly localize sub-cellularly to the cytoplasm; nascent miRNA transcripts exclusively localize subcellularly to the nucleus, while mature miRNA transcripts exclusively localize sub-cellularly to the cytoplasm. (A) Dorsal view of a whole-mount fluorescent ISH for smedwi-2 on an intact planarian; the arrow indicates the dorsal midline where it is analyzed by confocal microscopy in B-D. (B-D) Single confocal section of a labelling to detect smedwi-2 mRNA in red (B) and the nucleicounterstained with Hoechst $(C)$; the merged image is seen in $D$ where smedwi-2 labelling can be observed predominantly around the nucleus in the cytoplasm. However, with increased laser intensity, the staining can also be observed in the nucleus as two dots (B) (high magnification panel, double head arrows). (E) Dorsal view of a whole-mount fluorescent ISH for cintillo on an intact planarian; the image shows only the head of the intact planarian; the square indicates the group of cells which are analyzed by confocal microscopy in F-H. (F-H) Single confocal section of a labelling to detect cintillo mRNA in red (F) and the nuclei counterstained with Hoechst (G); the merged image is seen in $\mathrm{H}$ where cintillo labelling can be observed predominantly at the cytoplasm; F, G and $H$ are divided in two images, because they correspond to single confocal sections from different focal planes of the same sample. (I) Ventral view of a whole-mount fluorescent ISH for sme-mir-749 on an intact planarian; the arrow indicates the area which is analyzed

by confocal microscopy in J-L. (J-L) Single confocal section of a labelling to detect sme-mir-749 nascent transcript in red (J) and the nuclei counterstained with Hoechst (K); the merged image is seen in epidermal cells. (M) Ventral view of a whole-mount fluorescent ISH for sme-mir-87b on an intact planarian; the image shows only the head of the intact planarian; the arrow indicates the area which is analyzed by confocal microscopy in N-P. (N-P) Single confocal section of a labelling to detect sme-mir-87b nascent transcript in red (N) and the nuclei counterstained with Hoechst (O); the merged image is seen in $P$ where sme-mir-87b labelling can be observed as two dots; an area with higher laser confocal intensity shows that staining is still observed only in the nucleus (P, asterisk). (Q) Ventral view of a whole-mount fluorescent ISH for sme-mir-31b on an intact planarian; the image shows only the head of the intact planarian; the arrow indicates the area which is analyzed by confocal microscopy in R-T. (R-T) Single confocal section of a labelling to detect sme-mir-31b nascent transcript in red (R) and the nuclei counterstained with Hoechst (S); the merged image is seen in T where sme-mir-31b labelling can be observed as two dots. (U) Ventral view of a whole-mount fluorescent ISH for sme-let-7b on an intact
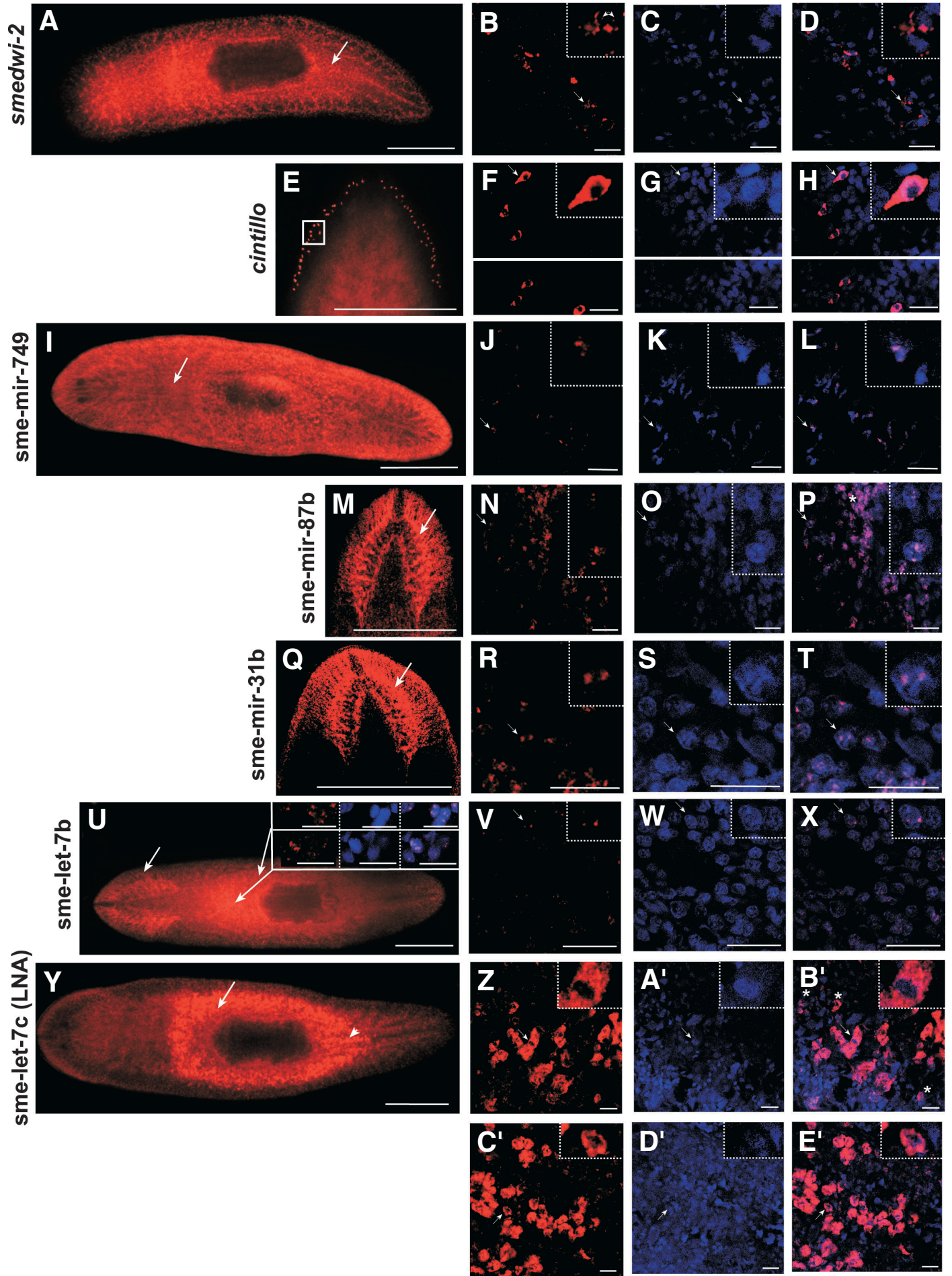
sion pattern in the sexual that we did not detect in the asexual strain. Some miRNAs are implicated by their expression patterns to be potential stem cell regulators and even germ stem cell regulators. This is the first Lophotrocozoan animal where miRNA expression patterns have been determined, albeit postembryonically. This is also the first time that sub-cellular localization of transcripts has been demonstrated in the planarian model system. We observe a broad set of miRNA expression patterns, many of them with conserved patterns with respect to their orthologs in other animals. These data provide an important starting point for the functional analysis of these miRNAs in planarians.

We can not rule out a technical basis for failure to detect the remaining miRNAs. However, it seems more likely they are being transcribed at low levels, are expressed during very precise regeneration stages we have not covered or are expressed only during starvation or other specific life history scenarios we did not test. Alternatively, the primary miRNA transcripts may be too short or processed too rapidly to be detected by this method.

It has been shown in the past 5 years that many vertebrate miRNAs are enriched in the nervous system, which is consistent with the complexity of neural cell identities and the necessity for neural cells to have a perfect spatio-temporal control of mRNA translation for assuring their synaptic development and plasticity (Kim et al., 2004; Sempere et al., 2004). It is now becoming increasingly evident that miRNAs are essential for synaptic development and that their misregulation might contribute to the etiology of neuronal diseases characterized by synaptic dysfunction (Fiore and Schratt, 2007; Schratt et al., 2006). An advantage of whole-mount ISH compared to Northern blot analysis is that not only temporal but also spatial patterns can be assessed. We have managed to show 36 miRNA loci patterns. Of these more than $70 \%$ have expression in the nervous system of intact asexual planarians. The expression of many of these miRNAs corresponds to a region suggested to be involved in signal transduction to the VNC (Nakazawa et al., 2003) suggesting a direct link between miRNAs with synaptic development. Although the planarian brain has long been considered as one of the "simplest" brains within the Bilateria (Keenan et al., 1981), it is now becoming evident that the planarian CNS and in particular the brain actually shows a complex cytoarchitecture that is functionally regionalized allowing the performance of complex processes (Cebrià et al., 2002; Nakazawa et al., 2003; Cebrià et al., 2007). A brain capable of complex responses to the environment within the context of an organism that is continuously remodelling its body (Morgan, 1898) including the CNS (Baguñà and Romero, 1981) must require a very precise regulation of synaptic development and plasticity. miRNAs may play an important role in this process, and the variety of miRNAs expressed in and in close proximity to the CNS supports this.

Emerging evidence suggests that miRNAs play an essential role in stem cell self-renewal and differentiation (Yang et al., 2001; Houbaviy et al., 2003; Kuwabara et al., 2004; Suh et al., 2004; Cheng et al., 2005; Forstemann et al., 2005; Hatfield et al., 2005; Kanellopoulou et al., 2005; Lee et al., 2005; Murchison et al., 2005; Tang et al., 2006; Yu et al., 2007). Almost $80 \%$ of the miRNAs are expressed in the planarian parenchyma. Of these we found that sme-mir-752/2d/71b, sme-mir-7b, sme-mir36, sme-mir-92, sme-mir-124a and sme-mir-124b, which are miRNAs with a typical neoblast-like pattern, are expressed in neoblasts/irradiation sensitive cells. sme-mir-7c has the same characteristic pattern indicative of neoblast expression, thus is very likely to be expressed in neoblasts although we could not confirm this unambiguously with our irradiation experiments.

We have found a group of miRNAs that appear to be expressed in the germline associated tissues in planarians. Of these smemir-36 and sme-mir-67 are also expressed in neoblasts/irradiation sensitive cells in asexual planarians. They have expression patterns that are the same as previously described markers of germ stem cells (Handberg-Thorsager and Saló, 2007) but different to markers of differentiated germ cells (Zayas et al., 2005). This suggests that the sme-mir-36 and sme-mir-67 miRNAs are expressed in germ stem cells. As yet little is known about the function of these conserved miRNAs in other systems. The finding that sme-lin-4c expression is not affected by irradiation suggests that it is not expressed in neoblasts and that its expression in germline tissues may be restricted to differentiated ova rather than germ stem cells. This agrees with its expression pattern centrally in the lumen of the ovary, compared to the more lateral/ peripheral expression of the other miRNAs.

The rest of the miRNAs expressed in the parenchyma show slightly different parenchyma patterns from the "typical neoblast" pattern (Reddien et al., 2005a). We found that sme-let-7c, smemir-2c/71c and sme-mir-67 are expressed in neoblasts/irradiation sensitive cells. But sme-mir-2a1/71a1, sme-mir-2a2/71a2, sme-mir-281 and sme-mir-745 that have very similar expression patterns were not affected by irradiation. For simplification we describe this pattern as "medial parenchyma, partial posterior midline, brain ganglia" (Table 1). However, we note that the irradiation insensitive expression patterns in this group (sme-mir2a1/71a1, sme-mir-2a2/71a2, sme-mir-281 and sme-mir-745) all have expression in the posterior midline just behind the pharynx (Area $A$ in blue in Supplementary Fig. 8). For those miRNA expression patterns in this group that were irradiation sensitive, the expression in the posterior midline is further posterior to area A (area B in dark brown in Supplementary Fig. 8). This suggests that the cells in area $A$ (irradiation insensitive) and area $B$ (irradiation sensitive) are distinct midline populations. In agreement with the existence of these cell populations, miRNAs with posterior midline expression immediately proximal to the pharynx (in area A) are not affected by irradiation and some miRNA expression patterns (sme-mir-7b, sme-mir-124a, sm-mir-124b and sme-mir-67) maintain expression in this subset of cells after irradiation, while expression is lost elsewhere (Supplementary Fig. 8). Other previously described genes show a similar pattern of expression in area $A$ (as well as elsewhere). For instance, smedinx-1 is expressed in this area (Oviedo and Levin, 2007) and its expression is not affected by irradiation. The marker TCEN49, expressed in most cell types except epidermal cells (Bueno et al., 1996; Vispo et al., 1996) and a Zinc-dependent metalloprotease (Sánchez Alvarado et al., 2002) are also expressed in the posterior midline just posterior to the pharynx. More studies need to be done to investigate the nature of these cells, what is clear is that they express a complex set of miRNAs.

An interesting observation is that there are diverse restricted expression patterns along the anterior-posterior (AP) axis in the 
parenchyma and nervous system that suggest a function for miRNAs in modulating or maintaining the AP polarity during planarian homeostasis. Examples include the posteriorly enhanced expression of sme-mir-124c (Fig. 1Z) or sme-mir-31b (Fig. 1U), sme-mir-Ea which is expressed in the posterior regions of the digestive system (Fig. 1C) and sme-mir-C (Fig. 1I) and smemir-1a (Supplementary Fig. 1B) which are expressed only in the mid-posterior excretory system.

An important caveat to our results is that nascent transcription may not precisely parallel the accumulation of mature miRNAs. While using LNA oligonucleotide probes would avoid this (Wienholds et al., 2005), as well as have lower background levels and larger number of target molecules for detection, the big disadvantage is that it is a technique not affordable for most labs. At least for sme-let-7c and sme-mir-67 there is a parallel accumulation of nascent transcripts and mature miRNAs and we believe this to be the case for most, but not all, miRNAs.

Our data gives the first expression patterns and the first insight into miRNA function in a Lophotrochozoan, the planarian Schmidtea mediterranea. Additionally, we now have an idea which miRNAs are expressed in the planarian stem cell population and may therefore be involved in self-renewal and differentiation. Once potential targets are identified by bioinformatic means, a greater insight into the role of miRNAs in various aspects of planarian biology will be possible. The functional study of miRNAs awaits the development of a reverse genetic technique capable of removing the expression of individual miRNAs. While morpholinos have been shown to work in other systems the multicellular nature of the planarian system prevents this approach in adult planarians. RNAi approaches can be used to investigate predicted miRNA targets that can be experimentally validated in other misexpression systems (Reddien et al., 2005b). Ultimately improvements in the currently limited transgenic approaches will allow miRNAs to be over-expressed and possibly their functions elucidated more directly (González-Estévez et al., 2003). The global impact and role of miRNAs may be assessed by studying the different components of the miRNA biogenesis pathway. Once this is done we will be able to better understand the role of miRNAs in regulating planarian homeostasis and regeneration and the roles of miRNAs in self-renewal and differentiation.

\section{Materials and Methods}

\section{Animals}

Planarians used in this work belong to the species Schmidtea mediterranea asexual strain originally provided by Dr. Emili Saló (University of Barcelona, Barcelona, Spain) and were collected in a fountain in Montjuïc, Barcelona, Spain. The sexual strain was collected in Sardinia, Italy. Animals were maintained at $19^{\circ} \mathrm{C}$, cultured in Trent (UK) river water and fed once per week with organic chicken liver. Animals were starved for one week prior to experiments.

\section{miRNAs nascent templates}

Genomic DNA extraction was done as described previously for nematodes (Aboobaker and Blaxter, 2003). BLAST searches were performed on an assembly of the $S$. mediterranea genome (http://genome.wustl.edu) to search for the genomic region surrounding the mature planarian miRNAs (miR base, http://microrna.sanger.ac.uk/). We generated $400 \mathrm{bp}$ $700 \mathrm{bp}$ templates (Supplementary table) with T7 promoters appended to the antisense strand, from all known planarian miRNA loci (Palakodeti et al., 2006). In most cases, the pre-miRNA hairpin resides in the center of this probe. Where multiple miRNAs reside in a small cluster, we designed one or multiple probes that span the cluster.

\section{LNA probes}

Two miRCURY'TM 5'-DIG LNA detection probes labelled were obtained from Exiqon (Vedbæk, Denmark): sme-let-7c (5'aacctttgagtcactacctca-3') and sme-miR-67 (5'-accctcgttcatggaggttgtga3').

\section{Whole-mount in situ hybridization experiments}

Digoxigenin-labelled RNA probes for the nascent templates were prepared by using an in vitro labelling kit (Roche, Basel, Switzerland). Whole mount ISH hybridization was carried out as described previously (Umesono et al., 1999) with the following modifications. Proteinase $\mathrm{K}$ treatment $(20 \mu \mathrm{g} / \mathrm{ml})$ was performed for $8 \mathrm{~min}$ on the asexual strain and for $12 \mathrm{~min}$ on the sexual strain. A triethanolamine treatment was performed as described by Nogi and Levin (2005). All the nascent probes were used to a concentration of $1 \mathrm{ng} / \mu \mathrm{l}$ and the hybridizations were carried out at $55^{\circ} \mathrm{C}$ for 17 hours. sme-let-7c LNA probe was used at a concentration of $1 \mathrm{nM}$ and the hybridizations were carried out at 54 ${ }^{\circ} \mathrm{C}$ for 17 hours. sme-miR-67 LNA probe was used at a concentration of $15 \mathrm{nM}$ and the hybridizations were performed at $57^{\circ} \mathrm{C}$ for 17 hours. All washes, for both nascent and LNA probes were performed at the corresponding hybridization temperature and as follows: $100 \%$ Hybridization solution for $15 \mathrm{~min}, 75 \%$ Hybridization solution / 25\% (2xSSC; $0.1 \%$ Triton $X-100$ ) for $10 \mathrm{~min}$; $50 \%$ Hybridization solution / 50\% (2xSSC; $0.1 \%$ Triton X-100) for $10 \mathrm{~min}$; $25 \%$ Hybridization solution / $75 \%$ (2xSSC; $0.1 \%$ Triton X-100) for $10 \mathrm{~min}$; two washes of (2xSSC; $0.1 \%$ Triton $X-100)$ for 30 min each; two washes of $(0.2 x S S C ; 0.1 \%$ Triton X-100) for 30 min each. For LNA probes, Tween-20 was used instead of Triton X-100 for the washes, in Buffer I and in Buffer II.

The developing time for some miRNAs was very short (up to 3 hours); however, some miRNAs required much more time (up to 8 hours) to develop, consequently resulting in more background. In the case of the two LNA probes the developing time was always very short compared to the corresponding nascent probe.

Samples were observed through a Zeiss Discovery V8 from Carl Zeiss and the images were taken with an AxioCam MRC from Carl Zeiss.

Positive controls (data not shown) for all ISH were performed with smed_noggin1 (Molina et al., 2007) and smedwi-2 (Reddien et al., 2005a).

\section{Whole-mount fluorescent in situ hybridization experiments}

Whole-mount fluorescent ISH hybridization was carried out as described previously (Cebrià et al., 2007) with the following modifications. Samples were developed using Tyramide Signal Amplification (Perkin Elmer) at a concentration of 1:50 in 1x Amplification Buffer for 20 minutes. Nuclei were stained with $0.5 \mu \mathrm{g} / \mathrm{ml}$ Hoechst 33342 overnight at $4{ }^{\circ} \mathrm{C}$

We observed that this protocol is perfectly adapted for those miRNAs whose expression usually develops in up to 3 hours using NBT/BCIP but it does not work for the rest.

Nascent and LNA probes were used at the same concentration as for the conventional ISH. The genes cintillo (Oviedo et al., 2003) and smedwi-2 (Reddien et al., 2005a) were used as controls.

Samples were mounted in SlowFade Antifade (Molecular Probes) to be analyzed in a Leica MZ16F fluorescence stereomicroscope and recorded on a Leica DFC 300Fx camera (Leica Lasertechnik, Heidelberg). Confocal laser scanning microscopy was performed with a Leica SP2 confocal laser scanning microscope (CLSM) (Leica Lasertechnik, Heidelberg).

\section{Irradiation}

Intact asexual and sexual planarians were irradiated at 96 Gy (6 Gy/ 
min for $16 \mathrm{~min}$ ) of gamma radiation using a sealed ${ }^{137} \mathrm{Cs}$ source (Gammacell-1000 Elite, Nordion, Kanata, Canada). Fixation for wholemount ISH was performed at 6 days post-irradiation.

\section{Acknowledgments}

We thank to Professor Emili Saló $i$ Boix for providing the Schmidtea mediterranea asexual strain. We thank to Ma Dolores Molina and Dr. Mette Handberg-Thorsager for providing the smed_noggin1 and smedwi2 clones respectively and to Dr. Francesc Cebrià and Phil Newmark for providing the cintillo and Smed-GluR EST clones. We are grateful to Dr. Francesc Cebrià for help with the fluorescent ISH protocol and discussion on the manuscript and to Dr. Susan Anderson from the confocal microscopy facility ( $A M U$, University of Nottingham). Work in AAA lab is supported by grants from the MRC, BBSRC and $A A A$ was supported by The Wellcome Trust International Research Fellowship during part of this work; CGE is funded by a Beatriu de Pinós fellowship (Generalitat de Catalunya, Catalunya, Spain).

\section{References}

ABOOBAKER, A.A. and BLAXTER, M.L. (2003). Hox gene loss during dynamic evolution of the nematode cluster. Curr Biol 13: 37-40.

ABOOBAKER, A.A., TOMANCAK, P., PATEL, N., RUBIN, G.M. and LAI, E.C. (2005). Drosophila micrornas exhibit diverse spatial expression patterns during embryonic development. Proc Natl Acad Sci USA 102: 18017-18022.

ÁLVAREZ-GARCÍA, I. and MISKA, E.A. (2005). Microrna functions in animal development and human disease. Development 132: 4653-4662.

BAGUÑÀ, J. (1976). Mitosis in the intact and regenerating planarian Dugesia mediterranea $\mathrm{n}$. Sp. li. Mitotic studies during regeneration and a possible mechanism of blastema formation. J. Exp. Zool. 195: 65-80.

BAGUÑÀ, J. and ROMERO, R. (1981). Quantitative analysis of cell types during growth, degrowth and regeneration in the planarians Dugesia mediterranea"and Dugesia tigrina. Hydrobiologia 84: 181-194.

BEREZIKOV, E., GURYEV, V., VAN DE BELT, J., WIENHOLDS, E., PLASTERK, R.H. and CUPPEN, E. (2005). Phylogenetic shadowing and computational identification of human microrna genes. Cell 120: 21-24.

BUENO, D., BAGUÑÀ, J. and ROMERO, R. (1996). A central body region defined by a position-specific molecule in the planarian Dugesia (Girardia) tigrina: Spatial and temporal variations during regeneration. Dev Biol 178: 446-458.

CARRANZA, S., BAGUÑÀ, J. and RIUTORT, M. (1997). Are the platyhelminthes a monophyletic primitive group? An assessment using $18 \mathrm{~s}$ rdna sequences. Mol. Biol. Evol. 14: 485-497.

CEBRIÀ, F., GUO, T., JOPEK, J. and NEWMARK, P.A. (2007). Regeneration and maintenance of the planarian midline is regulated by a slit orthologue. Dev Biol 307: 394-406.

CEBRIÀ, F., KOBAYASHI, C., UMESONO, Y., NAKAZAWA, M., MINETA, K. IKEO, K., GOJOBORI, T., ITOH, M., TAIRA, M., SÁNCHEZ ALVARADO, A. and AGATA, K. (2002). Fgfr-related gene nou-darake restricts brain tissues to the head region of planarians. Nature 419: 620-624.

CHENG, L.C., TAVAZOIE, M. and DOETSCH, F. (2005). Stem cells: From epigenetics to microRNAs. Neuron 46: 363-367.

CIMMINO, A., CALIN, G.A., FABBRI, M., IORIO, M.V., FERRACIN, M., SHIMIZU, M., WOJCIK, S.E., AQEILAN, R.I., ZUPO, S., DONO, M. et al. (2005). Mir-15 and mir-16 induce apoptosis by targeting bcl2. Proc Natl Acad Sci USA 102: 13944-13949.

DE MOOR, C.H., MEIJER, H. and LISSENDEN, S. (2005). Mechanisms of translational control by the $3^{\prime}$ utr in development and differentiation. Semin Cell Dev Biol 16: 49-58.

DUBOIS, F. (1949). Contribution á l'ètude de la migration des cellules de régénération chez les planaires dulcicoles. Bull Biol Fr Belg 93: 213-283.

DUNN, C.W., HEJNOL, A., MATUS, D.Q., PANG, K., BROWNE, W.E., SMITH, S.A., SEAVER, E., ROUSE, G.W., OBST, M., EDGECOMBE, G.D. et al. (2008). Broad phylogenomic sampling improves resolution of the animal tree of life. Nature 452: 745-749.

FIORE, R. and SCHRATT, G. (2007). MicroRNAs in vertebrate synapse develop- ment. Sci. World J. 7: 167-177.

FORSTEMANN, K., TOMARI, Y., DU, T., VAGIN, V.V., DENLI, A.M., BRATU, D.P. KLATTENHOFF, C., THEURKAUF, W.E. and ZAMORE, P.D. (2005). Normal microRNA maturation and germ-line stem cell maintenance requires loquacious, a double-stranded rna-binding domain protein. PLoS Biol 3: e236.

GONZÁLEZ-ESTÉVEZ, C., FELIX, D.A., ABOOBAKER, A.A. and SALÓ, E. (2007). Gtdap-1 promotes autophagy and is required for planarian remodeling during regeneration and starvation. Proc Natl Acad Sci USA 104: 13373-13378.

GONZÁLEZ-ESTÉVEZ, C., MOMOSE, T., GEHRING, W.J. and SALÓ, E. (2003) Transgenic planarian lines obtained by electroporation using transposonderived vectors and an eye-specific gfp marker. Proc Natl Acad Sci USA 100: 14046-14051.

GUO, T., PETERS, A.H. and NEWMARK, P.A. (2006). A bruno-like gene is required for stem cell maintenance in planarians. Dev Cell 11: 159-169.

HANDBERG-THORSAGER, M. and SALÓ, E. (2007). The planarian nanos-like gene smednos is expressed in germline and eye precursor cells during development and regeneration. Dev Genes Evol 217: 403-411.

HASE, S., KOBAYASHI, K., KOYANAGI, R., HOSHI, M. and MATSUMOTO, M. (2003). Transcriptional pattern of a novel gene, expressed specifically after the point-of-no-return during sexualization, in planaria. Dev Genes Evol 212: 585592.

HATFIELD, S.D., SHCHERBATA, H.R., FISCHER, K.A., NAKAHARA, K., CARTHEW, R.W. and RUOHOLA-BAKER, H. (2005). Stem cell division is regulated by the microRNA pathway. Nature 435: 974-978.

HOUBAVIY, H.B., MURRAY, M.F. and SHARP, P.A. (2003). Embryonic stem cellspecific micrornas. Dev Cell 5: 351-358.

HYMAN, L. (1951). The invertebrates: Platyhelminthes and rhynchocoela- the acoelomate bilateria. McGraw-Hill Book Company Inc., New York.

KANELLOPOULOU, C., MULJO, S.A., KUNG, A.L., GANESAN, S., DRAPKIN, R., JENUWEIN, T., LIVINGSTON, D.M. and RAJEWSKY, K. (2005). Dicer-deficient mouse embryonic stem cells are defective in differentiation and centromeric silencing. Genes Dev 19: 489-501.

KEENAN, C.L., COSS, R. and KOOPOWITZ, H. (1981). Cytoarchitecture of primitive brains: Golgi studies in flatworms. J Comp Neurol 195: 697-716.

KIM, J., KRICHEVSKY, A., GRAD, Y., HAYES, G.D., KOSIK, K.S., CHURCH, G.M and RUVKUN, G. (2004). Identification of many micrornas that copurify with polyribosomes in mammalian neurons. Proc Natl Acad Sci USA 101: 360-365.

KOSMAN, D., MIZUTANI, C.M., LEMONS, D., COX, W.G., MCGINNIS, W. and BIER, E. (2004). Multiplex detection of RNA expression in Drosophila embryos. Science 305: 846 .

KUWABARA, T., HSIEH, J., NAKASHIMA, K., TAIRA, K. and GAGE, F.H. (2004) A small modulatory dsRNA specifies the fate of adult neural stem cells. Cell 116: 779-793.

LAGOS-QUINTANA, M., RAUHUT, R., LENDECKEL, W. and TUSCHL, T. (2001) Identification of novel genes coding for small expressed RNAs. Science 294: 853-858.

LAGOS-QUINTANA, M., RAUHUT, R., YALCIN, A., MEYER, J., LENDECKEL, W and TUSCHL, T. (2002). Identification of tissue-specific microRNAs from mouse. Curr Biol 12: 735-739.

LAI, E.C. (2002). MicroRNAs are complementary to 3' UTR sequence motifs that mediate negative post-transcriptional regulation. Nat Genet 30: 363-364.

LAU, N.C., LIM, L.P., WEINSTEIN, E.G. and BARTEL, D.P. (2001). An abundant class of tiny RNAs with probable regulatory roles in Caenorhabditis elegans. Science 294: 858-862.

LEE, R.C. and AMBROS, V. (2001). An extensive class of small RNAS in Caenorhabditis elegans. Science 294: 862-864.

LEE, R.C., FEINBAUM, R.L. and AMBROS, V. (1993). The C. elegans-heterochronic gene lin-4 encodes small RNAs with antisense complementarity to lin-14. Cell 75: 843-854.

MELTZER, P.S. (2005). Cancer genomics: Small RNAs with big impacts. Nature 435: $745-746$

MOLINA, M.A., SALÓ, E. and CEBRIÀ, F. (2007). The BMP pathway is essential for re-specification and maintenance of the dorsoventral axis in regenerating and intact planarians. Dev Biol 311: 79-94.

MORGAN, T.H. (1898). Experimental studies of the regeneration of Planaria 
maculata. Archiv für Entwickelungsmechanik der organismen 7: 364-397.

MORGAN, T.H. (1900). Regeneration in planarians. Arch. Entw. Mech. Org. 10: 58119.

MURCHISON, E.P., PARTRIDGE, J.F., TAM, O.H., CHELOUFI, S. and HANNON, G.J. (2005). Characterization of dicer-deficient murine embryonic stem cells. Proc Natl Acad Sci USA 102: 12135-12140.

NAKAZAWA, M., CEBRIÀ, F., MINETA, K., IKEO, K., AGATA, K. and GOJOBORI, T. (2003). Search for the evolutionary origin of a brain: Planarian brain characterized by microarray. Mol Biol Evol 20: 784-791.

NOGI, T. and LEVIN, M. (2005). Characterization of innexin gene expression and functional roles of gap-junctional communication in planarian regeneration. $\mathrm{Dev}$ Biol 287: 314-335.

ORII, H., SAKURAI, T. and WATANABE, K. (2005). Distribution of the stem cells (neoblasts) in the planarian Dugesia japonica. Dev Genes Evol 215: 143-57.

OVIEDO, N.J. and LEVIN, M. (2007). Smedinx-11 is a planarian stem cell gap junction gene required for regeneration and homeostasis. Development 134: 3121-3131.

OVIEDO, N.J., NEWMARK, P.A. and SÁNCHEZ ALVARADO, A. (2003). Allometric scaling and proportion regulation in the freshwater planarian Schmidtea mediterranea. Dev Dyn 226: 326-333.

PALAKODETI, D., SMIELEWSKA, M. and GRAVELEY, B.R. (2006). MicroRNAs from the planarian Schmidtea mediterranea: A model system for stem cell biology. RNA 12: 1640-1649.

PASQUINELLI, A.E., MCCOY, A., JIMÉNEZ, E., SALÓ, E., RUVKUN, G., MARTINDALE, M.Q. and BAGUÑ்̀, J. (2003). Expression of the 22 nucleotide let-7 heterochronic rna throughout the metazoa: A role in life history evolution? Evol Dev 5: 372-378.

PROCHNIK, S.E., ROKHSAR, D.S. and ABOOBAKER, A.A. (2007). Evidence for a microRNA expansion in the bilaterian ancestor. Dev Genes Evol 217: 73-77.

REDDIEN, P.W., BERMANGE, A.L., MURFITT, K.J., JENNINGS, J.R. and SÁNCHEZ ALVARADO, A. (2005b). Identification of genes needed for regeneration, stem cell function, and tissue homeostasis by systematic gene perturbation in planaria. Dev Cell 8: 635-649.

REDDIEN, P.W., OVIEDO, N.J., JENNINGS, J.R., JENKIN, J.C. and SÁNCHEZ ALVARADO, A. (2005a). Smedwi-2 is a piwi-like protein that regulates planarian stem cells. Science 310: 1327-1330.

REINHART, B.J., SLACK, F.J., BASSON, M., PASQUINELLI, A.E., BETTINGER, J.C., ROUGVIE, A.E., HORVITZ, H.R. and RUVKUN, G. (2000). The 21nucleotide let-7 RNA regulates developmental timing in Caenorhabditis elegans. Nature 403: 901-906.

REUTER, M. and GUSTAFSSON, M.K. (1995). The flatworm nervous system: Pattern and phylogeny. EXS 72: 25-59.

ROBINS, H. and PRESS, W.H. (2005). Human microRNAs target a functionally distinct population of genes with AT-rich 3' UTRs. Proc Natl Acad Sci USA 102: 15557-15562.

RONSHAUGEN, M. and LEVINE, M. (2004). Visualization of trans-homolog enhancer-promoter interactions at the Abd-B hox locus in the Drosophila embryo. Dev Cell 7: 925-932.

Rossi, L., SAlVetTI, A., LeNA, A., BAtistoni, R., DERI, P., PuGliesi, C., LORETI, E. and GREMIGNI, V. (2006). Djpiwi-1, a member of the paz-piwi gene family, defines a subpopulation of planarian stem cells. Dev Genes Evol 216: 335-346.

ROSSI, L., SALVETTI, A., MARINCOLA, F.M., LENA, A., DERI, P., MANNINI, L., BATISTONI, R., WANG, E. and GREMIGNI, V. (2007). Deciphering the molecular machinery of stem cells: A look at the neoblast gene expression profile. Genome Biol 8: R62.

SALÓ, E. (2006). The power of regeneration and the stem cell kingdom: Freshwater planarians (platyhelminthes). Bioessays 28: 546-559.

SALVETTI, A., ROSSI, L., DERI, P. and BATISTONI, R. (2000). An mcm2-related gene is expressed in proliferating cells of intact and regenerating planarians.
Dev Dyn 218: 603-14.

SALVETTI, A., ROSSI, L., LENA, A., BATISTONI, R., DERI, P., RAINALDI, G., LOCCI, M.T., EVANGELISTA, M. and GREMIGNI, V. (2005). Djpum, a homologue of Drosophila pumilio, is essential to planarian stem cell maintenance. Development 132: 1863-1874.

SÁNCHEZ ALVARADO, A., NEWMARK, P.A., ROBB, S.M. and JUSTE, R. (2002). The Schmidtea mediterranea database as a molecular resource for studying platyhelminthes, stem cells and regeneration. Development 129: 5659-5665.

SCHRATT, G.M., TUEBING, F., NIGH, E.A., KANE, C.G., SABATINI, M.E., KIEBLER, M. and GREENBERG, M.E. (2006). A brain-specific microRNA regulates dendritic spine development. Nature 439: 283-289.

SEMPERE, L.F., FREEMANTLE, S., PITHA-ROWE, I., MOSS, E., DMITROVSKY, E. and AMBROS, V. (2004). Expression profiling of mammalian microRNAs uncovers a subset of brain-expressed microRNAs with possible roles in murine and human neuronal differentiation. Genome Biol 5: R13.

SHIBATA, N., UMESONO, Y., ORII, H., SAKURAI, T., WATANABE, K. and AGATA, K. (1999). Expression of vasa(vas)-related genes in germline cells and totipotent somatic stem cells of planarians. Dev Biol 206: 73-87.

STARK, A., BRENNECKE, J., BUSHATI, N., RUSSELL, R.B. and COHEN, S.M. (2005). Animal microRNAs confer robustness to gene expression and have a significant impact on 3'UTR evolution. Cell 123: 1133-1146.

SUH, M.R., LEE, Y., KIM, J.Y., KIM, S.K., MOON, S.H., LEE, J.Y., CHA, K.Y., CHUNG, H.M., YOON, H.S., MOON, S.Y. et al. (2004). Human embryonic stem cells express a unique set of microRNAs. Dev Biol 270: 488-498.

SUN, M., HURST, L.D., CARMICHAEL, G.G. and CHEN, J. (2005). Evidence for a preferential targeting of 3 '-UTRs by cis-encoded natural antisense transcripts. Nucleic Acids Res 33: 5533-5543.

TANG, F., HAJKOVA, P., BARTON, S.C., LAO, K. and SURANI, M.A. (2006). MicroRNA expression profiling of single whole embryonic stem cells. Nucleic Acids Res 34: e9.

UMESONO, Y., WATANABE, K. and AGATA, K. (1997). A planarian orthopedia homolog is specifically expressed in the branch region of both the mature and regenerating brain. Dev Growth Differ 39: 723-727.

UMESONO, Y., WATANABE, K. and AGATA, K. (1999). Distinct structural domains in the planarian brain defined by the expression of evolutionarily conserved homeobox genes. Dev Genes Evol 209: 31-39.

VISPO, M., CEBRIÀ, F., BUENO, D., CARRANZA, S., NEWMARK, P. and ROMERO, R. (1996). Regionalisation along the anteroposterior axis of the freshwater planarian dugesia(girardia)tigrina by tcen49 protein. Int J Dev Biol Suppl 1: 209S-210S.

WANG, Y., ZAYAS, R.M., GUO, T. and NEWMARK, P.A. (2007). Nanos function is essential for development and regeneration of planarian germ cells. Proc Natl Acad Sci USA 104: 5901-5906.

WIENHOLDS, E., KLOOSTERMAN, W.P., MISKA, E., ALVAREZ-SAAVEDRA, E., BEREZIKOV, E., DE BRUIJN, E., HORVITZ, H.R., KAUPPINEN, S. and PLASTERK, R.H. (2005). Microrna expression in zebrafish embryonic development. Science 309: 310-311.

YANG, S., TUTTON, S., PIERCE, E. and YOON, K. (2001). Specific doublestranded RNA interference in undifferentiated mouse embryonic stem cells. Mol Cell Biol 21: 7807-7816.

YOSHIDA-KASHIKAWA, M., SHIBATA, N., TAKECHI, K. and AGATA, K. (2007). Djcbc-1, a conserved dead box RNA helicase of the rck/p54/me31b family, is a component of RNA-protein complexes in planarian stem cells and neurons. Dev Dyn 236: 3436-50.

YU, F., YAO, H., ZHU, P., ZHANG, X., PAN, Q., GONG, C., HUANG, Y., HU, X., SU, F., LIEBERMAN, J. et al. (2007). Let-7 regulates self renewal and tumorigenicity of breast cancer cells. Cell 131: 1109-1123.

ZAYAS, R.M., HERNÁNDEZ, A., HABERMANN, B., WANG, Y., STARY, J.M. and NEWMARK, P.A. (2005). The planarian Schmidtea mediterranea as a model for epigenetic germ cell specification: Analysis of ESTs from the hermaphroditic strain. Proc Natl Acad Sci USA 102: 18491-18496. 


\section{Further Related Reading, published previously in the Int. J. Dev. Biol.}

See our Special Issue Evo-Devo edited by Jordi García-Fernández and Jaume Baguñà at: -http://www.ijdb.ehu.es/web/contents.php?vol=47\&issue=7-8

See our recent Special Issue Fertilization, in honor of David L. Garbers and edited by Paul M. Wassarman and Victor D. Vacquier at: http://www.ijdb.ehu.es/web/contents.php?vol=52\&issue=5-6

Planarian regeneration: achievements and future directions after 20 years of research Emili Saló, Josep F. Abril, Teresa Adell, Francesc Cebriá, Kay Eckelt, Enrique Fernández-Taboada, Mette Handberg-Thorsager, Marta Iglesias, M Dolores Molina and Gustavo Rodríguez-Esteban

Int. J. Dev. Biol. (2008) 52: 2414-2414

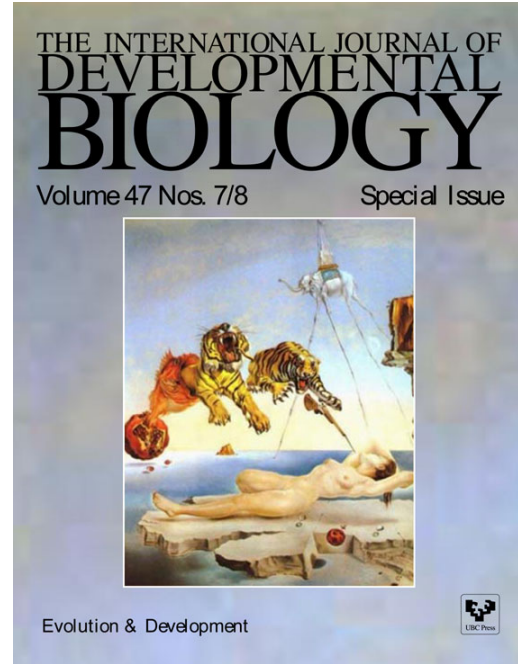

2006 ISI **Impact Factor $=3.577^{* *}$

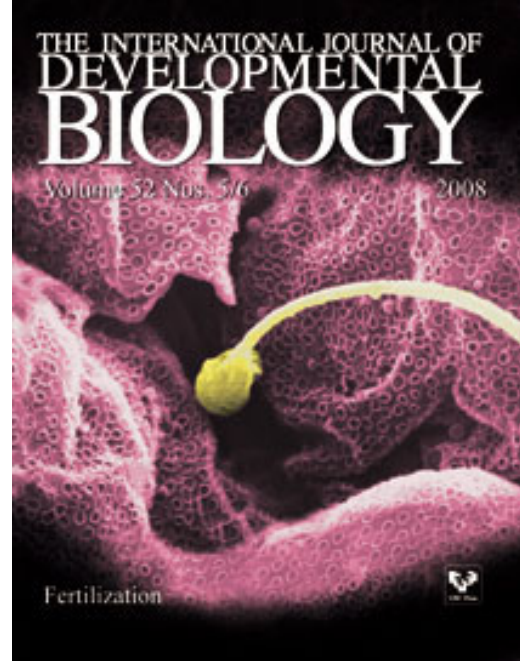

